\title{
STOMACH
}

\section{Human transforming growth factor $\alpha$ (TGF- $\alpha$ ) is digested to a smaller (1-43), less biologically active, form in acidic gastric juice}

\author{
T Marchbank, R Boulton, H Hansen, R J Playford
}

Gut 2002;51:787-792

See end of article for authors' affiliations

.....................

Correspondence to: Professor R J Playford Gastroenterology Section Imperial College School of Medicine, Hammersmith Hospital Campus, Du Cane Rd, London W12 ONN UK; r.playford@ic.ac.uk

Accepted for publication 30 April 2002

\begin{abstract}
Background: Transforming growth factor $\alpha$ (TGF- $\alpha$ ) is a 50 amino acid peptide with potent proliferative and cytoprotective activity present in gastric mucosa and juice.

Aims: To determine the forms and biological activity of natural and recombinant TGF- $\alpha$ following incubation with acid pepsin.

Patients: Human gastric juice was obtained under basal conditions from patients taking acid suppressants and from volunteers undergoing intragastric neutralisation.

Methods: Samples were analysed using mass spectroscopy and/or high pressure liquid chromatography with radioimmunoassay. Biological activity was determined using thymidine incorporation into rat hepatocytes and an indomethacin/restraint induced gastric damage rat model.

Results: TGF- $\alpha_{1-50}$ is cleaved to TGF- $\alpha_{1-43}$ by acid pepsin and this is the predominant form in normal gastric juice. However, intragastric neutralisation or taking acid suppressants caused the predominant form to be TGF- $\alpha_{1-50}$. TGF- $\alpha_{1-43}$ had only half of the ability to maximally stimulate $\left[{ }^{3} \mathrm{H}\right]$ thymidine incorporation into primary rat hepatocytes (28 177 (1 130) DPM/well for $2.16 \mathrm{nM} \mathrm{TGF- \alpha} \alpha_{1-43} v 63184$ (3536) $\mathrm{DPM} /$ well for TGF- $\left.\alpha_{1-50} ; p<0.001\right)$. A similar reduced potency was seen when used in an indomethacin induced rat gastric damage model $\left(0.18 \mu \mathrm{mol} / \mathrm{kg} / \mathrm{h}\right.$ of TGF- $\alpha_{1-43}$ reduced ulcer area by $19 \%$ whereas TGF- $\alpha_{1-50}$ reduced area by $\left.62 \% ; p<0.001\right)$.

Conclusions: TGF- $\alpha_{1-50}$ is cleaved to the TGF- $\alpha_{1-43}$ form by acid pepsin, causing 2-5-fold loss of biological activity. Such changes may have relevance to the actions of acid suppressants and the importance of this peptide in both normal and abnormal growth.
\end{abstract}

\section{MATERIAL AND METHODS}

\section{Materials}

Recombinant and purified native human TGF- $\alpha$ were obtained from Calbiochem (Nottingham, UK). Porcine pepsin was obtained from Sigma (P6887, Poole, UK) in the form of a lyophilised powder. All other chemicals were obtained from Sigma unless stated otherwise
Methods of analyses of samples to determine the forms of TGF- $\alpha$

Preparation of gastric juice samples prior to high pressure liquid chromatography (HPLC)

Samples of gastric juice which were to have HPLC performed were first concentrated using octadecylsilane (C18) cartridge chromatography, as described by Elson and colleagues. ${ }^{10}$ Eluates were then dried on a centrifugal evaporator (Savant; Farmingdale, New York, USA) and resuspended in $0.1 \%$ trifluoroacetic acid (TFA) prior to injection into the HPLC loop.

\section{Reverse phase HPLC}

Studies involving reverse phase HPLC used a Hewlett Packard 1100 (Stockport, UK) consisting of a quaternary pump delivery system, Rheodyne-7725 sample injector, and a $1 \mathrm{ml}$ injection loop. The column used was an analytical "Jupiter" C5, 300 A, $5 \mu \mathrm{m}(4.6 \times 150 \mathrm{~mm})$ column (Phenomenex UK Ltd). After application of the sample, the column was eluted isocratically ( $15 \%$ acetonitrile $(\mathrm{AcN}), 0.1 \% \mathrm{TFA}$ ) for 10 minutes before a gradient from $15-40 \%$ AcN, $0.1 \%$ TFA was run over 30 minutes. Samples were collected on a Foxy-Jr fraction collector and the system was controlled by a HP pentium PC with HP chemstation software. Samples were dried on a centrifugal evaporator and resuspended in water or Tris buffer prior to mass spectroscopy or radioimmunoassay, respectively.

Abbreviations: HPLC, high pressure liquid chromatography; $A c N$, acetonitrile; TFA, trifluoroacetic acid; EGF, epidermal growth factor; EGF-R, epidermal growth factor receptor; PPI, proton pump inhibitor; RIA radioimmunoassay; TGF- $\alpha$, transforming growth factor $\alpha$. 


\section{Radioimmunoassay (RIA) for TGF- $\alpha$}

TGF- $\alpha$-like immunoreactivity was measured using a commercial RIA kit (BT-350; Biomedical Technologies Inc., Stoughton, Massachusetts, USA). Briefly, tubes were incubated for 24 hours at $4^{\circ} \mathrm{C}$, and bound and free TGF- $\alpha$ were separated using 50 $\mu \mathrm{l} /$ tube of donkey antisheep antibody and $50 \mu \mathrm{l}$ of PEG followed by mixing and centrifugation at $2000 \mathrm{rpm}$ for 15 minutes at $4^{\circ} \mathrm{C}$. Typical results gave a maximal binding ratio ( $\mathrm{T}_{\max }$ tubes) of 0.5 and a non-specific binding ratio ( $\mathrm{T}_{0}$ tubes) of 0.03 . Sensitivity of the assay is $0.02 \mathrm{ng} /$ tube. This radioimmunoassay does not cross react with epidermal growth factor (EGF).

Pilot study to determine the effect of acid pepsin digestion of TGF- $a$ on immunoreactivity of TGF- $a$

Six aliquots of TGF- $\alpha$ were randomised to be incubated in either Tris buffer $(\mathrm{pH} 7)$ or $0.1 \mathrm{M} \mathrm{HCl}$, each containing pepsin at $1 \mathrm{mg} / \mathrm{ml}$, for one hour at $37^{\circ} \mathrm{C}$. At the end of the incubation period all samples were neutralised using $0.1 \mathrm{M} \mathrm{NaOH}$. Standard curves were then performed using all of these aliquots on a single day. Data were analysed by fitting three parameter logistic functions of $\log _{e}$ concentration by least squares. These showed a small but significant decrease in the immunoreactivity of TGF- $\alpha$ which had been treated with acid pepsin. Fifty per cent of maximal binding occurred at a concentration of $5.2 \mathrm{ng} / \mathrm{ml} \mathrm{TGF-} \alpha$ in Tris/pepsin standards and $2.0 \mathrm{ng} / \mathrm{ml} \mathrm{TGF-} \alpha$ in standard which had been treated with acid pepsin (significance of difference between 50\% maximum binding values $p<0.001$ ). Concentrations of TGF- $\alpha$ in gastric juice samples were determined taking into account these small differences in immunoreactivity of the intact and digested forms.

\section{Mass spectroscopy}

Molecular weight was assessed by mass spectroscopy using the technique of matrix assisted laser desorption time of flight with a Finnigan LaserMAT mass spectrophotometer (San Jose, California, USA). Samples were mixed with $0.5 \mu \mathrm{l}$ of alpha-cyano-4-hydroxycinnamic acid matrix ( $1 \%$ in $50 \%$ AcN, $0.1 \%$ TFA). Standards used were oxidised insulin $\beta$ chain (molecular weight 3496.9) and ubiquitin (molecular weight 8564.9). Our group have previously validated this technique for use in peptide sequence analyses. ${ }^{11}$

\section{Methods of analyses of biological activity In vitro assay \\ Background to method}

Primary rat hepatocytes provide a robust reproducible method for determining the biological activity of EGF-like molecules. We have previously used this method to compare and contrast the relative bioactivity of different EGF receptor ligands. ${ }^{12}$ The methodology is therefore described only briefly below.

Isolation and culture of hepatocytes

Hepatocytes were isolated from male Wistar rats by in situ collagenase perfusion and cultured in Williams E medium using the method of Selden and Hodgson. ${ }^{13}$ Preliminary studies showed that the addition of Tris buffer alone, pepsin in Tris buffer, or acid and pepsin (which was subsequently neutralised) to the hepatocytes had no effect on their function, as determined by basal thymidine uptake, or their ability to respond to a standard dose of TGF- $\alpha$ added to the wells. Cell viability, determined by the ability to exclude $0.2 \%$ trypan blue, was greater than $80 \%$ in all experiments.

\section{Thymidine incorporation}

To assess the percentage of cells entering DNA synthesis, $\left[{ }^{3} \mathrm{H}\right]$ thymidine $(2 \mu \mathrm{Ci} /$ well, $10 \mu \mathrm{l}$; Amersham International, Bucks, UK) was included in the cultures eight hours after the addition of test samples. The amount of $\left[{ }^{3} \mathrm{H}\right]$ thymidine incorporated was assessed biochemically, 18 hours after addition of thymidine. ${ }^{13}$ Cells were washed for 15 seconds with water using a Dynatech Multimash automatic cell harvester and solubilised by incubation at $37^{\circ} \mathrm{C}$ for one hour in $200 \mu \mathrm{l}$ of $1 \mathrm{M} \mathrm{KOH}$. Cell extract $(50 \mu \mathrm{l})$ was counted in a $\beta$ counter in $1 \mathrm{ml}$ of scintillant (Optiphase Safe; LKB-Pharmacia, Bromma, Sweden).

\section{Assay of biological activity of different forms of TGF- $\alpha$ in} vivo

The ability of TGF- $\alpha$ to prevent gastric damage by indomethacin and restraint in rats was assessed using previously validated methods. ${ }^{14}$ Under light ether anaesthesia, rats (male Sprague Dawley, 225-250 g) had two subcutaneous cannula inserted into the back of the neck and were then placed in Bullman restraint cages. Once the animals had recovered, a continuous subcutaneous infusion of saline or various doses and forms of TGF- $\alpha$ was started at $1 \mathrm{ml} / \mathrm{h}$ using a multi-syringe infusion pump (Harvard Apparatus, Massachusetts, USA). Thirty minutes later, $20 \mathrm{mg} / \mathrm{kg}$ of indomethacin were injected subcutaneously via the second cannulae. Animals were killed by stunning and cervical dislocation three hours later and their stomachs removed and inflated with $4 \mathrm{ml}$ of $10 \%$ formalin. The next day the stomachs were opened and placed in fresh formalin prior to assessment. The stomachs were randomly coded and all analyses of gastric damage were assessed blind. Total ulcerated area $\left(\mathrm{mm}^{2} / \mathrm{stomach}\right)$ was assessed using a dissecting microscope $(\times 10)$ with the aid of a square grid. The stomachs were then embedded in wax and the depth of damage assessed microscopically and given a microscopic ulcer score, as previously described.$^{15}$ Using this system, each stomach was given a score of 0 to 4 , with $0=$ no damage, $\mathrm{l}=$ one small erosion (less than $0.5 \mathrm{~mm}$ ), $2=$ two small or one large erosion (greater than $0.5 \mathrm{~mm}$ ), $3=$ two or more large erosions, and $4=$ any area of ulceration extending to the muscularis mucosa.

Ethics approval

Local ethics approval was obtained for studies involving human volunteers and subjects gave informed consent.

\section{Study protocols}

Study 1: stability of recombinant TGF- $\alpha$ in acid pepsin in vitro

Aliquots of $10 \mu \mathrm{g}$ of recombinant TGF- $\alpha$ were incubated in various solutions for one hour at $37^{\circ} \mathrm{C}$. These were: (a) isotonic saline; (b) $0.1 \mathrm{M} \mathrm{HCl}$; (c) Tris buffer ( $\mathrm{pH}$ 7.4) containing $1 \mathrm{mg} / \mathrm{ml}$ of pepsin; and (d) $0.1 \mathrm{M} \mathrm{HCl}$ containing $1 \mathrm{mg} / \mathrm{ml}$ of pepsin. All assay conditions were performed in quadruplicate. One of the samples from each condition was assessed using mass spectroscopy without further separation. The other three samples underwent HPLC. Following HPLC separation, each fraction was split into two. One half of the fraction was analysed by RIA and the other by mass spectroscopy. In addition, to ensure the biological relevance of our studies, $5 \mu \mathrm{g}$ aliquots of purified human TGF- $\alpha$ were incubated for one hour in saline or $\mathrm{HCl}$ plus pepsin and analysed in an identical fashion.

To determine how fast the digestion of TGF- $\alpha$ occurred in acid pepsin, $5 \mu \mathrm{g}$ of recombinant TGF- $\alpha$ were incubated in $1 \mathrm{ml}$ of acid pepsin at $37^{\circ} \mathrm{C}$ for 10 minutes; this was then immediately neutralised to $\mathrm{pH} 7 \mathrm{using} \mathrm{NaOH}$ and analysed as above.

Study 2: form of TGF- $\alpha$ present in normal human acidic and neutral gastric juice

Baseline gastric juice samples were obtained by aspiration from patients who had a nasogastric tube inserted for clinical reasons. Samples from six patients taking proton pump inhibitors (PPIs) for clinical reasons were compared with samples obtained from six control patients. $\mathrm{pH}$ was determined for all samples to ensure control samples had a pH of 3 or less and PPI samples had a pH of more than 4. Samples were 
screened for the presence of trypsin (using a standard spectrophometric method employing $N \alpha$-benzoyl-DL-argininep-nitroanilide) and bilirubin to ensure there was no contamination by pancreatic proteases. Samples that contained no detectable trypsin or bilirubin were frozen and stored at $-20^{\circ} \mathrm{C}$ prior to HPLC and RIA.

Study 3: changes in the form of intragastric TGF- $\alpha$ in response to intragastric neutralisation

Seven subjects took part in this study (six males, one female). After an overnight fast, a double lumen nasogastric tube was placed for continuous aspiration from the gastric antrum with infusion $20 \mathrm{~cm}$ proximally. For six subjects, the study comprised a 40 minute perfusion period with normal saline followed by 40 minutes of perfusion with $0.17 \mathrm{M}$ sodium bicarbonate. The seventh subject had an 80 minute perfusion period with saline alone. Perfusion was at $5 \mathrm{ml} / \mathrm{min}$ and all perfusates contained $5 \mathrm{~g} / \mathrm{l}$ of polyethylene glycol 4000 (subsequently assayed using a standard turbidometric method) to allow for correction for duodenal losses. Aspirates were collected continuously on ice into a beaker containing a $\mathrm{pH}$ electrode to allow the juice to be continuously titrated to $\mathrm{pH} 7$ using $\mathrm{NaOH}$. Samples were mixed thoroughly and stored in 10 minute batches. At the midpoint of each collection period, a $1 \mathrm{ml}$ sample was collected directly from the aspiration tubing to allow analysis of $\mathrm{pH}$ and pepsin activity. Neutralised samples which contained no detectable trypsin or bilirubin were frozen and stored at $-20^{\circ} \mathrm{C}$ prior to HPLC and RIA.

\section{Study 4: biological effects of changes in the form of} TGF- $\alpha$

Preparation of TGF- $a$

To determine the effect of acid pepsin digestion on the biological activity of TGF- $\alpha$, four aliquots of $100 \mu \mathrm{g}$ of previously pooled recombinant TGF- $\alpha$ were randomly allocated to be incubated for one hour at $37^{\circ} \mathrm{C}$ in either $1 \mathrm{ml}$ of 0.1 $\mathrm{M} \mathrm{HCl}$ containing $\mathrm{l} \mathrm{mg}$ pepsin (that would be expected to digest TGF- $\alpha$ ) or $1 \mathrm{ml}$ of Tris buffer $\mathrm{pH} 7.0$ containing $1 \mathrm{mg}$ pepsin (that would not be expected to digest TGF- $\alpha$ ). At the end of the incubation period, the stock solutions were neutralised to $\mathrm{pH}$ 7. Samples were separated by HPLC as previously described and fractions containing TGF- $\alpha_{1-43}$ and TGF- $\alpha_{1-50}$ identified by mass spectroscopy. Protein concentrations of the fractions were determined using a Biorad protein assay and samples were then diluted in Tris buffer containing $1 \mathrm{mg} / \mathrm{ml}$ bovine serum albumin to minimise adhesion to the container during storage. These solutions were then used to perform studies examining changes in bioactivity.

\section{In vitro assay}

Various concentrations (0-9 nM) of either intact TGF- $\alpha$ (Tris/ pepsin treated) or the acid pepsin treated TGF- $\alpha$ were added to the hepatocytes and thymidine incorporation determined 26 hours later. For both intact and acid pepsin treated TGF- $\alpha$, each dose of TGF- $\alpha$ was measured in quadruplicate in four separate wells.

In vivo gastric damaging study

Rats were randomised to receive saline (containing bovine serum albumin $0.2 \mathrm{mg} / \mathrm{ml}$ ), "intact" TGF- $\alpha$ (Tris-pepsin treated TGF- $\alpha$ ) at either 0.18 or $0.90 \mu \mathrm{mol} / \mathrm{kg} / \mathrm{h}$, or acid pepsin treated TGF- $\alpha$ at either 0.18 or $0.90 \mu \mathrm{mol} / \mathrm{kg} / \mathrm{h}$.

\section{Statistics}

Data from the hepatocyte assay were analysed using the Prism 2.0 computer package. Analysis of variance followed by $t$ testing was carried out: $p<0.05$ was taken as significant.

The gastric damaging model was analysed using analysis of variance followed by $t$ testing based on the mean square error and degrees of freedom obtained from the analysis of variance, as appropriate: $p<0.05$ was taken as significant.
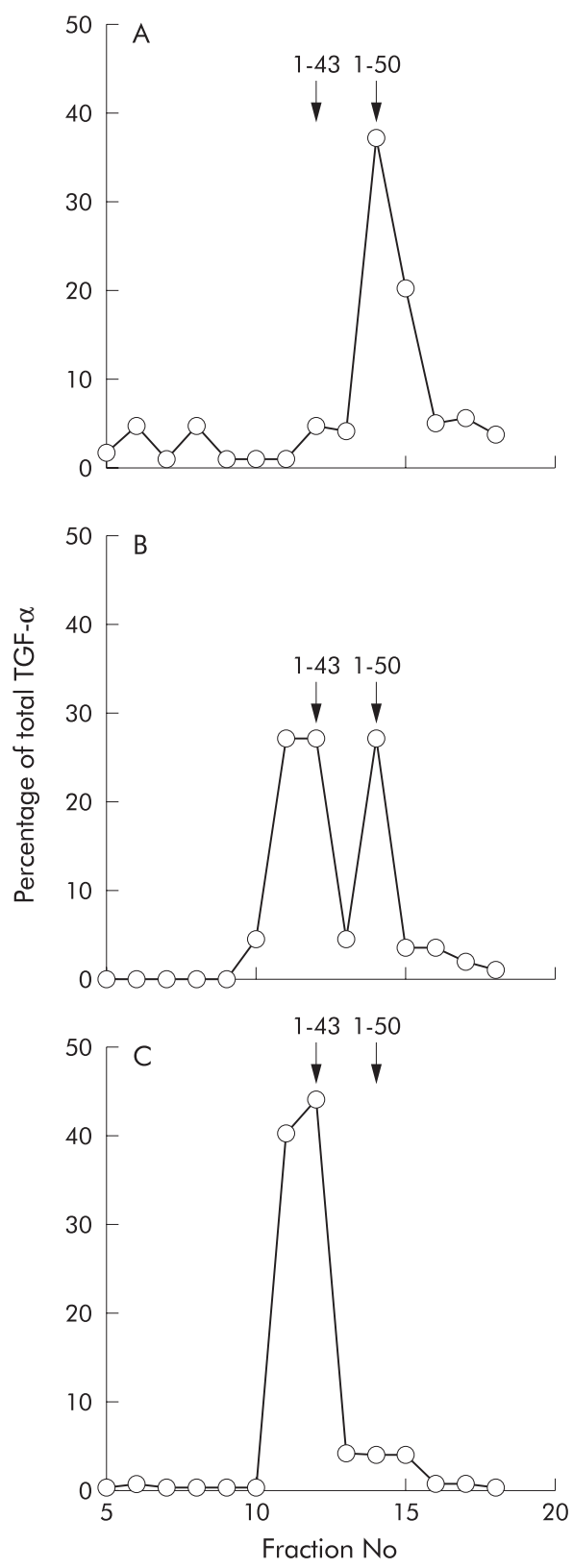

Figure 1 Stability of transforming growth factor $\alpha$ (TGF- $\alpha$ ) in acid and pepsin determined by reverse phase high pressure liquid chromatography and radioimmunoassay. TGF- $\alpha$ incubated in buffer (shown) or $\mathrm{HCl}$ alone (not shown) eluted as a single peak in fraction 14 (A). TGF- $\alpha$ that had been preincubated in acid and pepsin for 10 minutes eluted as two peaks equating to a mixture of TGF- $\alpha_{1-43}$ (fractions 11 and 12) and TGF- $\alpha_{1-50}$ (B). Incubation for a prolonged period ( 60 minutes) resulted in elution of a single peak equating to TGF- $\alpha_{1-43}(C)$.

\section{RESULTS}

Study 1: stability of recombinant TGF- $\alpha$ in acid pepsin in vitro

Intact recombinant TGF- $\alpha$, purified TGF- $\alpha$, TGF- $\alpha$ which had been incubated in $\mathrm{HCl}$ without pepsin, and Tris pepsin treated TGF- $\alpha$ gave a single peak on mass spectroscopy corresponding to intact TGF- $\alpha_{1-50}$. Measured mass was always in the range 5546-5554 (expected molecular weight of TGF- $\alpha$ 5546). In samples that were further analysed by performing HPLC followed by RIA, a single peak of immunoreactivity was found in fraction 14 (fig 1A). Mass spectroscopy of aliquots of this fraction also gave a mass corresponding to TGF- $\alpha_{1-50}$. 


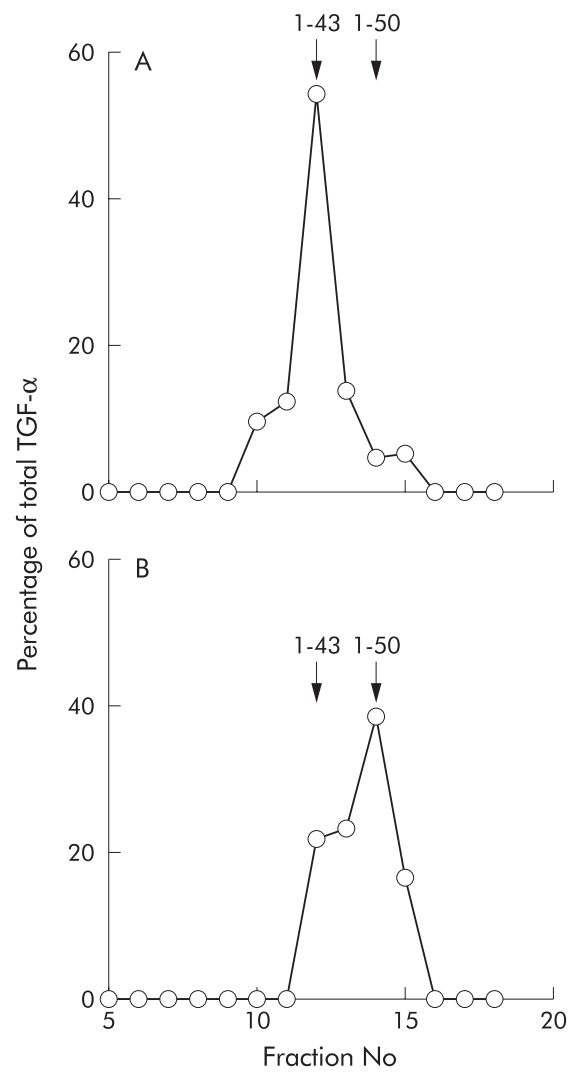

Figure 2 Influence of gastric $\mathrm{pH}$ on the forms of transforming growth factor $\alpha$ (TGF- $\alpha$ ) present in gastric juice. TGF- $\alpha$ present in resting normal gastric juice $(\mathrm{pH}<3)$ or collected during a saline wash eluted from high pressure liquid chromatography as a single peak in fractions 11 and 12, corresponding to TGF- $\alpha_{1-43}(A)$.

Changing the intragastric infusate to sodium bicarbonate caused the $\mathrm{pH}$ to rise to approximately 7 and the predominant form of TGF- $\alpha$ in the juice to be the 1-50 form (fraction 14) (B).

TGF- $\alpha$ which had been incubated for one hour in acid pepsin analysed by mass spectroscopy without HPLC separation gave one peak corresponding to TGF- $\alpha_{1-43}$ (measured molecular weight 4796, theoretical molecular weight 4796). HPLC separation followed by RIA showed one peak of immunoreactivity in fractions 11 and 12 (fig $1 C$ ). Mass spectroscopy of aliquots of these fractions also gave a mass corresponding to TGF- $\alpha_{1-43}$.

Following 10 minutes of incubation of TGF- $\alpha$ with acid pepsin, approximately $40 \%$ of TGF- $\alpha$ remained intact (fig 1B) with $60 \%$ of TGF- $\alpha$ being in the TGF- $\alpha_{1-43}$ form. TGF- $\alpha$ incubated in acid alone resulted in a peak in fraction 14 indicating intact TGF- $\alpha_{1-50}$ (as in fig 1A). Studies using native purified TGF- $\alpha$ gave similar results (data not shown)

\section{Study 2: form of TGF- $\alpha$ present in normal acidic and neutral gastric juice}

Gastric juice samples from control patients $(\mathrm{pH}<3)$ gave one peak corresponding to TGF- $\alpha_{1-43}$, which eluted in fractions 11 and 12, when analysed by HPLC and RIA. Gastric juice samples collected from two patients taking PPIs $(\mathrm{pH}>4)$ resulted in one peak in fractions 11 and 12 , corresponding to TGF- $\alpha_{1-43}$. However, gastric juice samples collected from four patients taking PPIs $(\mathrm{pH}>4)$ resulted in a split peak eluting in fractions 12 and 14, corresponding to TGF- $\alpha_{1-43}$ and TGF- $\alpha_{1-50}$, respectively, with approximately $40 \%$ of TGF- $\alpha$ eluting in the intact form. Total gastric juice TGF- $\alpha$ concentrations from the various subgroups were similar, giving a pooled value of 186 (41-839) ng/l (median (interquartile range)).

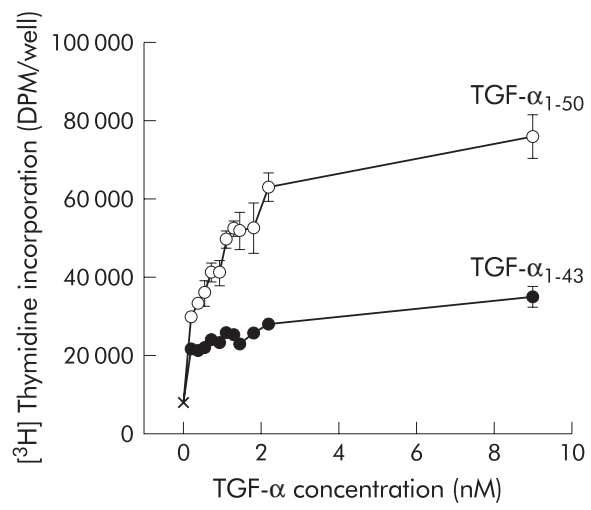

Figure 3 Effect of acid pepsin pretreatment on the biological activity of transforming growth factor $\alpha$ (TGF- $\alpha$ ) using hepatocytes as a bioassay. Recombinant TGF- $\alpha_{1-50}$ was pretreated by incubation in either pepsin in neutral Tris buffer (preserving the 1-50 form) or acid pepsin (causing digestion to the 1-43 form), followed by neutralisation. The biological activity of the samples were then compared by determining their ability to stimulate $\left[{ }^{3} \mathrm{H}\right]$ thymidine incorporation into primary rat hepatocytes. Each concentration was tested in quadruplicate. Acid pepsin treated TGF- $\alpha$ (TGF- $\left.\alpha_{1-43}\right)$ only resulted in $50 \%$ of the maximal stimulation of intact TGF- $\alpha$

$\left(\right.$ TGF- $\left.\alpha_{1-50}\right)$. For all doses studied, biological activity was greater for the TGF- $\alpha_{1-50}$ form versus the same dose of TGF- $\alpha_{1-43}(p<0.01$ for all doses greater than $0.54 \mathrm{nM}$ ).

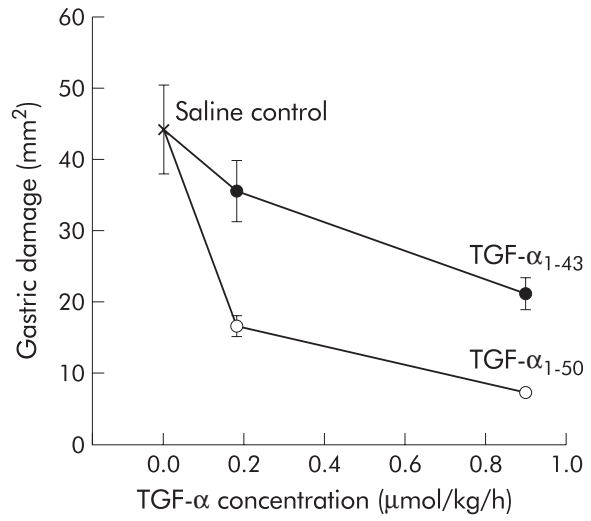

Figure 4 Effect of acid pepsin pretreatment on the biological activity of transforming growth factor $\alpha$ (TGF- $\alpha$ ) using attenuation of gastric damage as bioassay. Samples were treated as described in fig 3. Intact TGF- $\alpha$ (TGF- $\left.\alpha_{1-50}\right)$ or acid pepsin treated TGF- $\alpha$ (TGF- $\left.\alpha_{1-43}\right)$ was infused in various doses into animals that were restrained and given indomethacin $(20 \mathrm{mg} / \mathrm{kg})$. The mean surface area of damage (SEM) $\left(\mathrm{mm}^{2} /\right.$ stomach) is shown for each dose. Animals receiving intact TGF- $\alpha$ had less gastric damage than those receiving acid pepsin treated TGF- $\alpha(p<0.001) ; n=6-8$ per group.

\section{Study 3: changes in the forms of intragastric TGF- $\alpha$ in response to intragastric neutralisation}

Subjects receiving saline infusion all had a gastric $\mathrm{pH}$ of between 1.8 and 3.0. Prior to and during saline infusion, gastric samples showed that virtually all of the TGF- $\alpha$ eluted from the HPLC column in the position of TGF- $\alpha_{1-43}$ (fig 2A).

During bicarbonate perfusion, the $\mathrm{pH}$ of the samples were all in the range 6.8-7.2 and the peak of TGF- $\alpha$-LI corresponded to TGF- $\alpha_{1-50}$ with a slight shoulder in the position of TGF- $\alpha_{1-43}$ (fig $2 \mathrm{~B}$ ). The subject who had saline perfusion throughout showed no change in the form of TGF- $\alpha$ present during the final period (TGF- $\left.\alpha_{1-43}\right)$.

\section{Study 4: biological activity assays}

$\left[{ }^{3} \mathrm{H}\right]$ Thymidine uptake into primary rat hepatocytes

Both forms of TGF- $\alpha$ stimulated thymidine uptake in hepatocytes in a dose dependant manner (fig 3). However, maximal 
stimulation by $\mathrm{TGF}-\alpha_{1-50}$ was approximately double that caused by TGF- $\alpha_{1-43}$ (76447 (5654) v 35375 (2710) DPM/well for $9 \mathrm{nM}$ ). For all doses studied, biological activity was greater for the TGF- $\alpha_{1-50}$ form compared with the same dose of TGF- $\alpha_{1-43}(p<0.01$ for all doses greater than $0.54 \mathrm{nM})$

\section{Gastric damaging model}

Both forms of TGF- $\alpha$ decreased the amount of gastric damage in a dose dependent manner compared with the control (saline) group (fig 4). Analysis of variance showed a significant effect of both the dose $\left(\mathrm{F}_{1,29}=13.238, \mathrm{p}=0.0000\right)$ and form $\left(\mathrm{F}_{129}=20.597, \mathrm{p}=0.000\right)$ of TGF- $\alpha$. For both doses tested, TGF- $\alpha_{1-50}$ was significantly more potent than the TGF$\alpha_{1-43}$ form in its ability to reduce injury ( $p<0.01$, see fig 4$)$. Assessment using the microscopic damage score gave similar results (data not shown). An absolute quantitative comparison of the relative potencies of the two forms of TGF- $\alpha$ is not possible in this study. However, the area of damage seen in animals receiving $0.9 \mu \mathrm{mol} / \mathrm{kg} / \mathrm{h}$ of the TGF- $\alpha_{1-43}$ was slightly higher than that seen in animals receiving $0.18 \mu \mathrm{mol} / \mathrm{kg} / \mathrm{h}$ of TGF- $\alpha_{1-50}$ suggesting that, in this particular model, the intact form is about 3-5 times as potent as TGF- $\alpha_{1-43}$.

\section{DISCUSSION}

We have shown that TGF- $\alpha$ is susceptible to cleavage by acid pepsin in vivo and in vitro. Under normal basal acidic conditions, the predominant form in gastric juice is TGF- $\alpha_{1-43}$ but following intragastric neutralisation or in most patients taking clinically relevant doses of PPIs, the predominant form in gastric juice becomes the full length $\left(\mathrm{TGF}-\alpha_{1-50}\right)$ form. We have also shown that the acid pepsin digested TGF- $\alpha_{1-43}$ has about half to one fifth of the biological activity of the intact TGF- $\alpha_{1-50}$ molecule.

Mass spectroscopy provides a rapid sensitive method of determining the molecular weight of test peptides and is capable of demonstrating minor "clipping" of peptides which are not seen using simple size exclusion analyses. Mass spectroscopy is however not quantitative and is less useful in analysing peptides in complex biological solutions which may contain multiple peptides of similar molecular weight. We therefore used it in conjunction with HPLC and RIA to determine qualitative and quantitative changes in the forms of TGF- $\alpha$.

For the in vitro studies, a variety of cells of gastrointestinal origin were available. Carcinoma cell lines of colonic (for example, HT29) or gastric (for example, AGS) origin have previously been used by us and other groups to assess proliferative and antiproliferative activity of various peptides. These cells have the advantage of being derived from the human gastrointestinal epithelium and being relatively easy to culture. However, they also have the disadvantages of being obtained from carcinoma cell lines and, of particular relevance for the present study, of having a relatively flat dose-response curve. We therefore decided to use the rat hepatocyte system as it provides a robust reproducible model for examining growth factor activity and we have previous experience of its reliability in assessing the biological activity of other EGF receptor ligands. ${ }^{12}$ It provides a highly reproducible doseresponse curve and is of particular value for examining growth factor activity in intestinal juice as hepatocytes are not adversely affected by normal small intestinal luminal contents. ${ }^{14}$ It cannot be used however to assess changes in cell number as under the conditions used, hepatocytes complete cell DNA synthesis but cell division occurs infrequently and no net increase in cell number is seen. ${ }^{16}$

There are many well validated acute models of gastric injury. We chose the indomethacin/restraint model as our in vivo assay system because peptic ulceration due to nonsteroidal anti-inflammatory drugs is a major source of morbidity and mortality in humans ${ }^{17}$ and we have previously used it to examine the influence of peptic digestion on the EGF molecule. ${ }^{18}$

TGF- $\alpha$ is produced in the mucosa throughout the gastrointestinal tract ${ }^{1}$ and is synthesised as a 160 amino acid precursor molecule that spans the cell membrane. Subsequent exposure of the external domain to specific proteases releases the soluble mature 50 amino acid form ${ }^{19}$ which has a molecular weight of 5546 and includes three Cys-Cys double bonds. TGF- $\alpha$ shares $33 \%$ sequence homology with EGF and has nearly identical biological activity, acting through the same EGF receptor (EGF-R), also known as the erbB-1 receptor. There is continuing controversy as to whether erbB-l receptors are present on the apical (luminal) surface in addition to the basolateral membrane of the normal bowel. ${ }^{20-23}$ However, there is general agreement that luminal administration of erbB-1 ligands can stimulate growth and repair, acting via the luminal surface, when administered to the damaged bowel of both rats ${ }^{24}$ and humans. ${ }^{25}$

Our studies have shown that, under acidic conditions, pepsin cleaved the ${ }^{43} \mathrm{Cys}-{ }^{44} \mathrm{Glu}$ bond of the TGF- $\alpha$ molecule. Several isoforms of pepsin exist which differ slightly in their preferred substrate specificity and $\mathrm{pH}$ profile. ${ }^{26}$ However, we have previously shown that the vast majority of gastric proteolytic activity is dependant on an acidic $\mathrm{pH}$ with proteolytic activity markedly diminishing when $\mathrm{pH}$ rises to 4 or above. $^{18}$ Inactivation of pepsin therefore almost certainly explains the finding of the change in predominant form to TGF- $\alpha_{1-50}$ which was seen in patients taking PPIs or during intragastric neutralisation. Our in vitro study on the stability of native TGF- $\alpha$ in acid pepsin gave similar results to those found using recombinant TGF- $\alpha$. However, caution should always be shown before assuming recombinant peptides behave in an identical fashion to their native forms.

The concentration of TGF- $\alpha$ in gastric juice found in our studies (about $200 \mathrm{ng} / \mathrm{l}$ ) is similar to that reported by others, ${ }^{27}$ being about one third of that of EGF ( $500 \mathrm{ng} / \mathrm{l}$ ). The function of TGF- $\alpha$ in gastric juice is unclear although several lines of evidence suggest pathophysiological relevance: TGF- $\alpha$ is a potent stimulant of proliferation of several gastrointestinal cell lines in vitro, ${ }^{2-5}$ protects against injury and/or stimulates repair in several different animal models of gastrointestinal injury (for example, see Konturek and colleagues ${ }^{7}$ and Romano and colleagues ${ }^{8}$ ), and physiological concentrations of gastric juice TGF- $\alpha$ are probably sufficient to stimulate proliferation of human gastric explants. ${ }^{28}$ In addition, pathophysiological relevance for this concentration of TGF- $\alpha$ in gastric juice is supported by the finding that sialadenectomy of rats reduces the amount of EGF present in gastric juice by about $60 \%$ (approximately $300 \mathrm{ng} / \mathrm{l}$ ), which is similar to the receptor ligand contribution from TGF- $\alpha$ (200 ng/l), causing an increased susceptibility to noxious agents with increased ulceration and delayed healing. ${ }^{29}$ Taken together, these results suggest an important role for gastric juice TGF- $\alpha$, working in combination with EGF, in maintaining epithelial integrity. It is also important to note that virtually all previous studies measuring TGF- $\alpha$ in gastric juice have used immunoassays. Our finding that the immunoreactivity of the digested form is reduced is therefore important as it may lead to underestimation of gastric levels of TGF- $\alpha$ under acidic conditions unless appropriate corrections are made.

Indomethacin causes damage to the gastrointestinal tract by several mechanisms, including reduction of mucosal prostaglandin levels, reduction of mucosal blood flow, stimulating neutrophil activation, and possibly also stimulating apoptosis. ${ }^{30}$ It is likely that many of these mechanisms will be influenced by the presence of the TGF- $\alpha$. Both forms of TGF- $\alpha$ significantly reduced indomethacin induced gastric damage when administered at both 0.18 and $0.9 \mu \mathrm{mol} / \mathrm{kg} / \mathrm{h}$. The lower dose of TGF- $\alpha$ probably did not affect gastric acid secretion $^{31}$ but the higher dose may have done so because 1.8 
$\mu \mathrm{mol} / \mathrm{kg} / \mathrm{h}$ of TGF- $\alpha_{1-50}$, administered intravenously, decreases gastric acid secretion by $72 \% .^{31}$ This may be relevant to the mechanism by which TGF- $\alpha$ decreased gastric damage in our rat model as we have previously shown the damage to be acid dependant. ${ }^{15}$ Cleavage of the terminal seven amino acids of TGF- $\alpha$ caused a 3-5 fold reduction in its ability to reduce injury in this model, which was similar to the reduction in activity found using the in vitro assay. The results of the in vivo study are likely to be due to reduced interaction of circulating TGF- $\alpha_{1-43}$ with its receptors on gut cells. Alteration in the circulating half-life of the truncated form remains a possibility but is much less likely in view of the comparable data from in vitro studies.

Tam and colleagues ${ }^{32}$ examined which areas of the TGF- $\alpha$ molecule played a key role in its interaction with the erbB-1 receptor. They found that the seven $\mathrm{C}$ terminal amino acids have a major influence on its ability to bind and stimulate mitogenesis of rat kidney fibroblasts, with TGF- $\alpha_{1-43}$ having only $1 / 1000$ of the activity of $\mathrm{TGF}_{1-50}$. This is a much lower level of bioactivity than found in our studies although Tam et al did not perform any in vivo studies. Importantly, in their studies, TGF- $\alpha_{1-43}$ was produced using solid phase peptide synthesis, rather than recombinant technology, and the authors specifically mention the difficulties of obtaining correct refolding of TGF- $\alpha_{1-43}$ using this method. The different cell lines used (rat kidney fibroblasts $v$ primary rat hepatocytes) may also be relevant.

Recent studies examining the effect of knockout of EGF-R ligands suggest that EGF-R ligands function in a synergistic fashion with deletion of an individual member having relatively little effect on phenotype ${ }^{33} 34$ whereas multiple knockouts or deletion of the EGF-R itself resulting in profound effects on the gut. ${ }^{35}{ }^{36}$ The current series of studies suggest that changing the size of the TGF- $\alpha$ molecule from the truncated form to TGF- $\alpha_{1-50}$, as found in most patients taking PPIs, is biologically equivalent to a $2-3$ fold increase in TGF- $\alpha$ concentration. We have previously shown a similar reduction in gastric EGF bioactivity in response to acid and pepsin. ${ }^{18}$ The current findings therefore support the idea that luminal $\mathrm{pH}$ is likely to have a major influence on multiple luminal growth factors within the gastric juice. This may well have relevance to pro-healing activity (as seen with acid suppressants) and also conditions associated with abnormal growth, such as patients with pernicious anaemia or severe atrophic pangastritis (who fail to make gastric acid) and are known to have an increased risk of development of gastric carcinoma. ${ }^{37}$ Further studies appear warranted.

\section{Authors' affiliations}

T Marchbank, R J Playford, Imperial College Faculty of Medicine, Department of Gastroenterology, Hammersmith Hospital, Du Cane Road, London W12 ONN, UK

R Boulton, Department of Gastroenterology, Middlesex Hospital, Sterling Way, Edmonton, London N18 1QX, UK

H Hansen, Imperial Cancer Research Fund, Lincolns Inn Fields, London W2C 2PX, UK

\section{REFERENCES}

1 Cartlidge SA, Elder JB. Transforming growth factor- $\alpha$ and epidermal growth factor levels in normal human gastrointestinal mucosa. $\mathrm{Br} J$ Cancer 1989;60:657-60.

2 Chen MC, Lee AT, Soll AH. Mitogenic response of canine fundic epithelial cells in short-term culture to transforming growth factor alpha and insulin like growth factor. J Clin Invest 1991;87:1716-23.

3 Di Marco E, Pierce JH, Aaronson SA, et al. Mechanisms by which the EGF receptor and TGFalpha contribute to malignant transformation. Nat Immun Cell Growth Regul 1990:9:209-21.

4 Jankowski J. Altered gene expression of growth factors and their receptors during oesophageal tumorigenesis. Gastroenterol Clin Biol 1994;18:D40-5

5 Rutten MJ, Dempsey PJ, Soloman T, et al. Transforming growth factor alpha (TGF $\alpha$ ) is a potent mitogen for primary cultures of guinea pig gastric mucous epithelial cells. Am J Physiol 1991;265:G361-9.
6 Goodlad RA, Lee CY, Ghatei MA, et al. Differential effects of EGF and TGF $\alpha$ on gastrointestinal cell proliferation. Proc Nutr Soc 1993;52:185A

7 Konturek SJ, Brzozowski T, Majka J, et al. Transforming growth factor alpha and epidermal growth factor in protection and healing of gastric mucosal injury Scand J Gastroenterol 1992;27:649-55.

8 Romano M, Polk WH, Awad JA, et al. Transforming growth factor a protection against drug-induced injury to rat gastric mucosa in vivo. J Clin Invest 1992;90:2409-21

9 Konturek JW, Konturek SJ, Stachura J, et al. Helicobacter pylori-positive peptic ulcer patients do not adapt to aspirin. Aliment Pharmacol Ther 1998; 12:857-64

10 Elson SD, Browne CA, Thorburn GD. Extraction and purification of murine epidermal growth factor. Biochem Int 1984;8:427-35.

11 Pappin DJC, Hojrup P, Bleasby AJ. Rapid identification of proteins by peptide mass finger printing. Curr Biol 1993;3:327-32.

12 Calnan DP, Fagbemi A, Berlanga-Acosta J, et al. Potency and stability of $\mathrm{C}$ terminal truncated human epidermal growth factor. Gut 2000;47:622-7.

13 Selden AC, Hodgson HJF. Further characterisation of hepatotropin, a high molecular weight hepatotrophic factor in rat serum. J Hepatol 1989;9:167-76.

14 Playford RJ, Watanabe P, Woodman AC. Effect of luminal growth factor preservation on intestinal growth. Lancet 1993;314:843-8.

15 Playford RJ, Vesey DA, Haldane S, et al. Dose-dependent effects of fentanyl on indomethacin-induced gastric damage. Digestion 1991;49:198-203.

16 Richman RA, Claus TH, Pilkis SJ, et al. Hormonal stimulation of DNA synthesis in primary cultures of adult rat hepatocytes. Proc Natl Acad Sci USA 1976;73:3589-93.

17 Fenn GC. Review article: controversies in NSAID-induced gastroduodenal damage-do they matter? Aliment Pharmacol Ther 1994;8:815-26.

18 Playford RJ, Marchbank T, Calnan DP, et al. Epidermal growth factor is digested to smaller, less active forms in gastric juice. Gastroenterology 1995; 108:92-101.

19 Dernyck R. Transforming growth factor $\alpha$ : structure and biological activities. J Cell Biol 1986:32:293-304

20 Kelly D, McFadyen M, King TP, et al. Characterisation and autoradiographic localisation of the epidermal growth factor receptor in the jejunum of neonatal and weaned pigs. Reprod Fertil Dev 1992;4:183-91.

21 Scheving LA, Shiurba RA, Nguyen TD, et al. Epidermal growth factor receptor of the intestinal enterocyte: localisation to laterobasal but not brush border membrane. J Biol Chem 1989;264:1735-41.

22 Playford RJ, Hanby A, Gschmeissner S, et al. The epidermal growth factor receptor (EGF-R) is present on the basolateral, but not the apical surface of enterocytes in the human gut. Gut 1996;39:262-6.

23 Thompson JF. Specific receptors for epidermal growth factor in rat intestinal microvillus membranes. Am J Physiol 1988;254:G429-35.

24 Itoh M, Imai S, Joh T, et al. Effect of epidermal growth factor in combination with sucralfate or omeprazole on the healing of chronic gastric ulcers in the rat. J Clin Gastroenterol 1990;12:S187-91.

25 Matsuo Y, Gotoh Y, Itoh M, et al. Randomized, double blind comparison of epidermal growth factor from human urine (MG 111 ) with the active placebo in treatment of gastric ulcer. Hellenic J Gastroenterol 1992;5(suppl):217

26 Roberts NB, Taylor WH. Action of human pepsins 1, 2, 3 and 5 on the oxidised beta chain of insulin. Biochem J 1979;179:183-90.

27 Kataoka $\mathbf{H}$, Joh T, Kato KT, et al. Mitogenic properties of human gastric ivice. Dig Dis Sci 1997;42:1747-54.

28 Dutta SK, Matossian H, Hamburger A, et al. Effect of low cellular concentrations of epidermal growth factor and human saliva on cellular proliferation of gastric mucosal explants. Gastroenterology 1987:92:1378.

29 Rao RK, Thomas DW, Pepperl S, et al. Salivary epidermal growth factor plays a role in protection of ileal mucosal integrity. Dig Dis Sci 1997;42:2175-81.

30 Levi S, Shaw-Smith C. Non steroidal antiinflammatory drugs: how do they damage the gut? Br J Rheumatol 1994;33:605-12.

31 Grupcev G, Wallin C, Emas S, et al. Transforming growth factor $\alpha$ and epidermal growth factor inhibit gastric acid secretion and stimulate release of somatostatin and neurotensin in the conscious rat. Regul Pept 1994;52:111-18

32 Tam JP, Lin YZW, Wang DX, et al. Mapping the receptor-recognition site of human transforming growth factor $\alpha$. Int J Pept Protein Res 1991;38:204-11.

33 Luetteke NC, Qiu TH, Fenton SE, et al. Targeted inactivation of the EGF and amphiregulin genes reveals distinct roles for EGF receptor ligands in mouse mammary development. Development 1999;126:2739-50.

34 Mann GB, Fowler KJ, Gabriel A, et al. Mice with a null mutation of the TGF $\alpha$ gene have abnormal skin architecture, wavy hair, and curly whiskers and often develop corneal inflammation. Cell 1993;73:249-61.

35 Miettinen PJ, Berger JE, Meneses J, et al. Epithelial immaturity and multiorgan failure in mice lacking epidermal growth factor receptor. Nature 1995:376:337-41.

36 Troyer KL, Luetteke NC, Saxon M, et al. Growth retardation, duodenal lesions, and aberrant ileum archtecture in triple null mice lacking EGF, amphiregulin and TGF $\alpha$. Gastroenterology 2001;121:68-78.

37 Jedrychowski W, Popiela T, Steindorf K, et al A topographic analysis of atrophic gastritis and stomach cancer risk. Cent Eur J Public Health 1997;5: 117-21 


\section{LETTER}

If you have a burning desire to respond to a paper published in Gut, why not make use of our "rapid response" option?

Log onto our website (www.gutjnl.com), find the paper that interests you, and send your response via email by clicking on the "eletters" option in the box at the top right hand corner.

Providing it isn't libellous or obscene, it will be posted within seven days. You can retrieve it by clicking on "read eletters" on our homepage.

The editors will decide as before whether to also publish it in a future paper issue.

\section{Bleeding peptic ulcer}

We read with interest the paper on prediction of therapeutic failure after adrenaline injection plus heater probe treatment in patients with bleeding peptic ulcer by Wong and colleagues (Gut 2002;50:322-5). Even though the authors qualified their generalisation, the statement that "elderly patients often succumb to their concomitant illnesses rather than the bleeding itself" needs to be challenged as being unnecessarily defeatist, given the fact that timeliness of surgical intervention ${ }^{1}$ and, as shown below, postoperative management at the intensive care level, may be more crucial to survival than comorbidity as such.

\section{Case report}

A 70 year old woman with congestive cardiac failure (including radiographically validated left ventricular failure) and chronic obstructive airways disease experienced an episode of haematemesis and melaena with an associated blood pressure of $78 / 48 \mathrm{~mm} \mathrm{Hg}$ on the 1 March 2002, which was the eighth day of her hospital stay. Endoscopy revealed a large actively bleeding duodenal ulcer, which was managed with endoscopic haemostasis, rapidly followed by definitive laparotomy and under running of the bleeding vessel. She was then transferred to a neighbouring hospital for postoperative intensive care management, and this included a 24 hour period of artificial ventilation. On the 1lth postoperative day, having been repatriated to our hospital, she was clinically much improved even though her arterial blood tensions while breathing room air were as follows: partial oxygen tension $\left(\mathrm{paO}_{2}\right) 4.9 \mathrm{kPa}$ (normal range 10-14), partial carbon dioxide tension $\left(\mathrm{paCO}_{2}\right) 6.9 \mathrm{kPa}$ (normal range 4.5-6.1), and oxygen saturation $70 \%$, with concurrent transcutaneous oxygen saturation $72 \%$ (normal range 95$98 \%$ ). Her clinical status continued to improve on diuretics, angiotensin converting enzyme inhibitors, bronchodilators, and supplemental oxygen. On her 25 th postoperative day, lung function tests revealed a one second forced expiratory volume (FEV $)$ of 0.86 litres $(40 \%$ predicted), forced vital capacity (FVC) of 1.59 litres (61\% predicted), and an $\mathrm{FEV}_{1} / \mathrm{FVC}$ ratio of $54 \%$ (typically less than $70 \%$ in airflow obstruction). She could now perform a modified version of the "shuttle" walk ${ }^{2}$ for a distance of $30 \mathrm{~m}$ briskly, without stopping for breath, and also without supplemental oxygen. Repeat arterial blood gas tensions on 30 March 2002 showed $\mathrm{paO}_{2} 7.7 \mathrm{kPa}$ and $\mathrm{paCO}_{2}$ $5.8 \mathrm{kPa}$ while breathing room air.

\section{Comment}

On the basis of age, comorbidity, shock at presentation, and endoscopic stigmata of recent haemorrhage, this patient had a high risk of death with or without surgical intervention. ${ }^{3}$ Only timely intervention and impeccable postoperative care could tip the scales in her favour, hence the successful outcome documented here.

O M P Jolobe, A A BenHamida, B Basu-Chaudhuri

Department of Adult Medicine, Tameside General Hospital, Fountain Street, Ashton under Lyne OL6 9RW, UK

\section{References}

1 Wheatley KE, Snyman JH, Brearley S, et al. Mortality in patients with bleeding ulcer when those aged 60 or over are operated on early. Br Med J 1990;301:272.

2 Singh SJ, Morgan MDL, Scott S, et al. Development of a shuttle walking test of disability in patients with chronic airways obstruction. Thorax 1992;47: 1019-24.

3 Rockall TA. Management and outcome of patients undergoing surgery after acute upper gastrointestinal haemorrhage. J $R$ Soc Med 1998:91:518-23.

\section{CORRECTIONS}

The authors of Marchbank et al (Gut 2002;51:787-92) in the December issue of the journal, have noted a typographical error in their paper. In the results section, it should state that the $\mathrm{pH}$ of the two subjects who were taking proton pump inhibitors who did not show a change to the larger form of TGF $\alpha$ had a $\mathrm{pH}$ of less than, and not greater than 4 as published. The authors apologise for the error.

The following errors occurred in the paper "Prospective study of liver dysfunction in pregnancy in Southwest Wales" in the December issue by Ch'ng et al (Gut 2002;51:876-80) as final author corrections were not included. The published version does not clearly distinguish those patients in whom pre-eclampsia was the sole identifiable cause of liver dysfunction from those in whom pre-eclampsia co-existed with another cause such as HELLP syndrome, obstetric cholestasis, or sepsis. The corrections are to the abstract, tables 1,2, and 3, and part of the text of the results section on page 878 under the sub-heading "Diagnoses accounting for abnormal liver tests", and to two of the references. The journal apologises for the errors.

In the abstract, under methods, the second sentence should read "Patients with abnormal liver tests were assessed and followed througout and after pregnancy. Medical advice was provided to obstetric teams."

\section{Pregnancy specific conditions}

Pre-eclampsia was a common underlying abnormality seen in 68 patients $(48 \%)$ but was the sole identifiable cause of liver dysfunction in only 15. Complete ${ }^{6}$ and incomplete ${ }^{78}$ HELLP syndrome occurred in 30 patients of whom 29 were pre-eclamptic making this the commonest diagnosis accounting for abnormal liver tests. In most of those patients with incomplete or partial HELLP syndrome, the platelet count dropped abruptly by more than $50 \%$ in parallel with abnormal liver tests. OC was diagnosed in 23 patients (16\%); two of whom had preeclampsia. Eleven patients (8\%) had deranged LFT associated with hyperemesis gravidarum and all responded well to conservative management or oral steroids; none of these developed pre-eclamptic liver dysfunction later in pregnancy. AFLP was diagnosed in five patients $(4 \%)$, three of whom needed prolonged post-natal hospitalisation because of multi-organ involvement; none of these five patients had pre-eclampsia. Clinical details of these patients have been presented and published recently. ${ }^{11}{ }^{12}$

In "Other contributory conditions" the first sentence should read "Seventeen patients had abnormal liver tests in association with sepsis,

Table 1 Aspartate aminotransferase (AST), gamma glutamyl transpeptidase ( $\gamma \mathrm{GT})$, and bilirubin values for specific pregnancy related liver disorders

\begin{tabular}{lclr}
\hline & AST $(\mathrm{U} / \mathrm{I})$ & $\gamma \mathrm{GT}(\mathrm{U} / \mathrm{I})$ & \multicolumn{1}{c}{ Bilirubin $(\mu \mathrm{mol} / \mathrm{I})$} \\
\hline HELLP syndrome & $66(41-4123)$ & $24(6-209)$ & $13(4-155)$ \\
Obstetric cholestasis & $210(30-519)$ & $29(8-278)$ & $14(6-34)$ \\
Pre-eclamptic liver dysfunction alone & $68(36-210)$ & $18(7-51)$ & $7(3-12)$ \\
Hyperemesis gravidarum & $51(9-280)$ & $23(2-64)$ & $25(4-33)$ \\
AFLP & $278(86-542)$ & $50(22-209)$ & $50(19-61)$ \\
\hline
\end{tabular}

Values are median (range).

HELLP, haemolysis, elevated liver enzymes, low platelets; AFLP, acute fatty liver of pregnancy. 
Table 2 Diagnoses accounting for abnormal liver tests

\begin{tabular}{|c|c|c|c|c|c|c|}
\hline & $\mathrm{n}$ & $\begin{array}{l}\text { No with } \\
\uparrow \text { AST }\end{array}$ & $\begin{array}{l}\text { No with } \\
\uparrow \gamma G T\end{array}$ & $\begin{array}{l}\text { No with } \\
\uparrow \text { bilirubin }\end{array}$ & $\begin{array}{l}\text { No with } \\
\uparrow \text { urate }\end{array}$ & $\begin{array}{l}\text { No with } \\
\text { low platelets }\end{array}$ \\
\hline \multicolumn{7}{|l|}{ Group 1-Pregnancy specific } \\
\hline $\begin{array}{l}\text { HELLP syndrome }(5 \text { complete, } \\
25 \text { partial) }\end{array}$ & 30 & 30 & 12 & 10 & 29 & 30 \\
\hline Obstetric cholestasis & 23 & 22 & 10 & 2 & 17 & 0 \\
\hline Pre-eclampsia alone & 15 & 14 & 4 & 0 & 13 & 0 \\
\hline Hyperemesis gravidarum & 11 & 7 & 4 & 5 & 3 & 1 \\
\hline Acute fatty liver of pregnancy & 5 & 5 & 3 & 4 & 5 & 3 \\
\hline Hepatic infarct/haematoma & 1 & 1 & 1 & 1 & 1 & 1 \\
\hline \multicolumn{7}{|l|}{ Group 2-Other conditions } \\
\hline Postoperative (caesarean section) & 22 & 21 & 10 & 3 & 21 & 7 \\
\hline Sepsis & 17 & 17 & 6 & 2 & 12 & 2 \\
\hline Placental pathologies & 12 & 11 & 4 & 3 & 9 & 3 \\
\hline Diabetes & 8 & 6 & 5 & 1 & 5 & 4 \\
\hline Drug related & 4 & 1 & 4 & 1 & $\mathrm{~N} / \mathrm{A}$ & 2 \\
\hline Bile duct stones & 3 & 3 & 2 & 2 & 1 & 0 \\
\hline Hepatitis C & 2 & 2 & 1 & 0 & 0 & 0 \\
\hline Group 3-Diagnosis obscure & 14 & 8 & 4 & 1 & 6 & 0 \\
\hline
\end{tabular}

Table 3 Timing of liver dysfunction. Onset of specific pregnancy related liver disorders (in weeks' gestation)

\begin{tabular}{ll}
\hline HELLP syndrome & $36(25-38)$ \\
Obstetric cholestasis & $35(21-39)$ \\
Pre-eclamptic liver dysfunction & $37(25-40)$ \\
Hyperemesis gravidarum with liver dysfunction & $9(6-14)$ \\
AFLP & $38(32-38)$
\end{tabular}

Values are median (range)

HELLP, haemolysis, elevated liver enzymes, low platelets; AFLP, acute fatty liver of pregnancy.

most commonly caused by urinary tract infection ( 9 patients); 5 of these 17 were also pre-eclamptic."

References 11 and 12 should be as follows:

11 Ch'ng CL, Morgan M, Kingham JG. Acute fatty liver of pregnancy in South Wales, UK. J Hepatol 2002;36(Suppl 1):186.

$12 \mathrm{Ch}^{\prime}$ ng CL, Morgan M, Kingham JGC. Acute fatty liver of pregnancy in South Wales, UK. Gastroenterology 2002; 123(Suppl 1):53

Authors affiliations are:

C L Ch'ng, J G C Kingham, Department of Gastroenterology, Singleton Hospital, Swansea, UK

M Morgan Department of Obstetrics and Gynaecology, Singleton Hospital, Swansea, UK I Hainsworth Department of Clinical Pathology,

Morriston Hospital, Swansea, UK

\section{NOTICES}

The national register of hepatitis $C$ infections with a known date of acquisition.

The register steering group invite clinical and epidemiological researchers to submit proposals to accessdata held in the register. It is envisaged that a variety of studies might benefi from linkage with or access to the register, and proposals from all specialties and institutions are welcomed. Any researchers interested in applying for access to information held within the national register should contact the register co-ordinator (see below) for a list of available data and an application form. Study proposals should then be submitted to the register co-ordinator by 16 December 2002.
Further information: Dr Helen Harris (Register Co-ordinator) or Ms Lisa Beck (Research Assistant), Immunisation Division, Communicable Diseases Surveillance Centre, Public Health Laboratory Service, 61 Colindale Avenue, London NW9 6EQ. Tel: +44 (0)20 8200 6868 ext 4496; fax: +44 (0)20 82007868 ; email: $\quad$ hharris@phls.nhs.uk or lbeck@phls.nhs.uk

\section{7th International Workshop on Therapeutic Endoscopy}

This will be held on 3-5 December 2002 in Hong Kong. Further information: Professor SC Sydney Chung, Endoscopy Centre, Prince of Wales Hospital, Shatin, NT, Hong Kong. Tel: +852 2632 2233; fax: +852 2635 0075; email info@hksde.org

\section{Advances in the Inflammatory Bowel Diseases}

This conference will take place on 6-7 December 2002 in New York, USA. Further information: Heather Drew, Imedex, 70 Technology Drive, Alpharetta, GA 30005-3969, USA. Tel: +1 770751 7332; fax: +1 770751 7334; email: h.drew@imedex.com; website: www.imedex.com

\section{5th European Intensive Course (SMIER) Digestive Endoscopy}

This course will take place on 16-17 December 2002 in Strasbourg, France. Further information: Michele Centonze Conseil, 6 bis Rue des Cendriers, 75020 Paris, France. Tel: +33 1 446268 80: fax: + 33143496858 .
The Future of Gastro-enterohepato-pancreatology is bright

This Academic Farewell Symposium of Guido NJ Tytgat will be held on 12 December 2002 in Amsterdam, the Netherlands. Deadline for registration is 1 November 2002 (no registration fee) and registration should be done via email to: j.goedkop@amc.uva.nl.

\section{Cancer of Oesophagus and Gastric Cardia: from Gene to Cure}

This conference will be held on 13-15 December 2002 in Amsterdam, The Netherlands. Further information: European Cancer Centre, PO Box 9236, NL 1006 AE Amsterdam, The Netherlands. Tel: +31 (0)20 3462547 ; fax: +31 (0)20346 2525; email: ecc@ikca.n

\section{Imaging of the Abdomen: an Update}

This will be held on 23-24 January 2003 in Amsterdam, the Netherlands. Further information: visit the website www.epgs.nl or email epgs@amc.uva.nl. Tel: +31 20566 3926/ 4386.

\section{Surgery of the Foregut}

This meeting will be held on 17-18 February 2003 in Florida, USA. Further information: Cleveland Clinic Florida, Office of CME, 2950 Cleveland Clinic Boulevard, Weston, FL 3331 USA. Tel: + 1954659 5490; (toll free: + l 866 293 7866); fax: +1 954659 5491; email cme@ccf.org 